\title{
Penggunaan Media Sosial Instagram dalam Pembelajaran Kanji
}

\author{
${ }^{1}$ Asep Achmad Muhlisian, ${ }^{2}$ Yuliani Kusuma Putri \\ ${ }^{1,2)}$ STBA YAPARI ABA Bandung \\ 1asepachmad@stba.ac.id, 2yuliani.putri@stba.ac.id
}

DOI: $10.18196 /$ jjlel.3230

\begin{abstract}
Abstrak
Penelitian ini berjudul "Penggunaan Media Sosial Instagram dalam Pembelajaran Kanji, melihat masih banyak mahasiswa yang merasa kesulitan mempelajari kanji terutama dalam mengingat kanji yang disebabkan oleh beberapa hal berdasarkan observasi awal yakni kecilnya minat mahasiswa bahasa Jepang terhadap kanji dan banyak anggapan sulitnya mempelajari kanji. Objek dalam penelitian ini adalah mahasiswa bahasa Jepang semester 5 yang secara aktif menggunakan Instagram. Penelitian ini menggunakan metode action research. Hasil analisis data menunjukkan bahwa dari 435 mahasiswa yang memposting kanji melalui Instagram, sebagian besar menggunakan fitur-fitur yang ada di Instagram dan menyesuaikannya dengan kemampuan mereka mengingat kanji, seperti dengan asosiasi gambar, video yang menarik dan video urutan penulisan kanji.
\end{abstract}

Kata Kunci: Media Sosial; Instagram; Kanji

\begin{abstract}
This research entitled "Use of Instagram in Kanji Learning, sees that still many students who have difficulty in learn kanji, especially in remembering kanji caused by several things based on preliminary observations of the lack of interest of Japanese students in kanji and many consider it is difficult to learn kanji. The object of this research is the 5th semester Japanese language students who are actively using Instagram. This research used action research method. Data analysis result showed that of the 435 students who posted kanji via Instagram, most of them used features on Instagram and adjusted them to their ability to remember kanji, such as by association of images, interesting videos and videos of kanji writing sequences.
\end{abstract}


Keywords: Social Media; Instagram; Kanji

\section{Pendahuluan}

Hampir seluruh aspek kehidupan manusia seperti gaya hidup, interaksi sosial, pendidikan dan aspek lainnya tidak bisa terlepas dari media sosial. Menurut Prensky (2001), Abad ke 21 adalah era digitalisasi, di mana semuanya menjadi digital. Usia ini telah membawa pada lahirnya digital native, yakni anak-anak yang lahir di era digital. Kementerian Komunikasi dan Informatika (Kemenkominfo) pada tahun 2015 menyatakan bahwa internet di Indonesia telah digunakan oleh 63 juta orang dan sebagian besar merupakan pengguna media sosial. Panji (2014) menyatakan bahwa terdapat tiga fungsi dari internet yakni untuk mencari informasi, berkomunikasi dan untuk kebutuhan hiburan.

Hasil penelitian oleh We Are Social, perusahaan asal Inggris yang bergerak di bidang media dan bekerja sama dengan Hootsuite, menyimpulkan bahwa sebagian besar orang Indonesia menggunakan waktu sampai tiga jam lebih dalam sehari untuk dapat mengakses media sosial. Selanjutnya, Pertiwi (2018) pun mengungkapkan bahwa, dari total penduduk Indonesia sekitar 265juta orang, yang aktif menggunakan sosmed mencapai sekitar 130 juta.

Melihat kondisi tersebut, Putri (2014:869) berpendapat bahwa bagi para pendidik harus dapat dengan cepat mengadaptasikan diri, agar generasi selanjutnya dapat bersaing dan bekerjasama sesuai dengan perkembangan zaman, dan hal ini bukanlah tugas yang mudah. Meskipun anak-anak dapat secara otomatis terbiasa hidup di abad 21, orang tua tidak boleh mengalihkan perhatian dan sebaliknya kita harus terus memantau perkembangan mereka. Nilai didaktik jaringan sosial elektronik ditentukan oleh kemampuan untuk menyediakan interaksi kelompok. Terbukti bahwa Jejaring Sosial Elektronik (ESN) dapat bertindak sebagai sarana kegiatan 


\section{VOL. 3, NO. 2 AGUSTUS 2019

pelatihan kolaboratif, sarana penyebaran kontak sosial, perluasan interaksi sosial semua peserta dalam proses pendidikan (Pinchuk, 2016:83).

Pendidik pun harus memahami kehidupan, persaingan, dan tantangan di era digital ini untuk mengarahkan anak didiknya ke jalur yang benar. Pendidik harus memahami skill yang dibutuhkan oleh siswa untuk bertahan hidup di zaman ini.

Berdasarkan UU no.14 tahun 2005 mengenai guru dan dosen, yang salah satu pasalnya paling berhubungan dengan perkembangan media sosial sekarang ini adalah menuntut pendidik untuk memiliki kompetensi yang salah satunya adalah pendidik diharapkan "Menguasai dan memanfaatkan teknologi informasi dan komunikasi dalam pembelajaran". Selain itu pendidik diminta untuk dapat memanfaatkan teknologi yang ada untuk berkomunikasi dan pengembangan diri, dan dengan memanfaatkan media sosial dalam pembelajaran merupakan salah satu cara untuk melaksanakan Undang undang tersebut.

Paul Webster, seorang Brand Development Lead Instagram (APAC) mengatakan bahwa sampai sekarang Instagram telah mencapai empat ratus juta pengguna aktif di dunia, dan dari 25\% pengguna Instagram tahun ini, lebih dari setengahnya berdomisili di Asia dan Eropa. Indonesia merupakan negara dengan jumlah pengguna Instagram yang sangat dominan dan sekitar 89\% pengguna berusia 18-34 tahun.

Aftoniya (2016) mengungkapkan kelebihan instagram, yaitu:

1. Bersifat pribadi.

2. Terdapat fitur untuk mengedit foto.

3. Menuliskan Follower dan Following pengguna.

4. Follower tanpa batas.

5. Sangat mudah digunakan.

6. Dapat melihat foto orang lain

7. Terkoneksi dengan media sosial lainnya

8. Dapat menunggah video meskipun dalam durasi terbatas

Dengan melihat kelebihan dari Instagram, berkaitan pemanfaatan Instagram dalam pembelajaran, peneliti berpendapat bahwa pendidik harus dapat 
selektif dalam memilih fitur Instagram yang dapat dipakai secara efektif dan membantu mahasiswa dalam pembelajaran, terutama dalam pembelajaran Bahasa Jepang.

Dalam pembelajaran Bahasa Jepang terdapat empat huruf yang digunakan untuk menulis, yaitu hiragana, katakana, kanji, dan romaji. Kanji sendiri merupakan huruf yang melambangkan makna dan mempunyai dua cara baca yaitu kunyomi dan onyomi dan kanji merupakan salah satu mata kuliah yang dianggap sulit yang dipelajari dalam pembelajaran bahasa Jepang (Prasetiani, 2013).

Prasetiani (2013) pun mengatakan kanji dikenal di Jepang melalui Cina sekitar abad ke-4 pada masa dinasti Kan, sehingga kanji merupakan gabungan dari „kan' yang mengandung pengertian dinasti Kan, dan "ji' yang artinya huruf. Kanji sendiri adalah hyoo'i moji atau huruf yang menyatakan arti tertentu.

Menurut Sudjianto dan Dahidi (2009: 56-70) huruf kanji memiliki karakteristik, yakni memiliki bushu, atau kanji yang menjadi dasar pengklasifikasian kanji. Selain itu, kanji memiliki kakusuu, atau jumlah coretan yang membentuk kanji. Lalu, kanji memiliki hitsujun atau urutan coretan yang harus ditulis sesuai kaidah, dan terakhir kanji terdapat yomikata atau cara baca.

Kanji merupakan huruf yang paling sulit bermasalah dalam proses pembelajaran mahasiswa. Kanji banyak menimbulkan permasalahan terutama dalam hal kemampuan membaca, menulis dan mengingat dikarenakan jumlah kanji yang begitu banyak dan cara baca yang bervariasi. Selain cara menulis yang harus berurutan dan tidak boleh kurang coretan, cara membaca yang lebih dari satu bunyi pun menyulitkan pembelajar dalam mempelajari kanji (Prasetiani, 2013). Sudah banyak penelitian sebelumya yang berusaha menggunakan metode dan teknik dalam mengingat kanji, diantaranya Sherly Ferro Lensun dalam Jurnal Pendidikan Bahasa dan Sastra 


\section{VOL. 3, NO. 2 AGUSTUS 2019 \\ 185}

menulis artikel yang berjudul "Peningkatan Penguasaan Kanji dengan Metode Nemonik melalui Multimedia". Menurut Lensun(2016) Kegiatan Belajar Mengajar (KBM) yang dilakukan dengan menggunakan metode mnemonik dengan alat, kertas bergambar dan berwarna yang menarik pada multimedia memungkinkan mahasiswa mampu mengevaluasi sendiri terhadap pembelajaran kanji, seperti mengurutkan langkah-langkah penulisan dan praktik langsung cara baca. Mahasiswa pun banyak yang senang dengan metode nemonik dan responya pun sangat positif terhadap metode ini Penelitian Lensun lebih banyak berfokus kepada metode dan tidak secara spesifik menunjukkan media yang dipakai dlam pengembangan metode tersebut.

Penelitian lain yakni Dyah Prestiani dalam Jurnal Bahasa, Sastra dan Budaya Jepang menulis artikel yang berjudul "Meningkatkan Kemampuan Membaca Kanji Melalui Media Flashcard Power Point" Prestiani(2013) menyatakan bahwa media flashcard power point efektif untuk digunakan dalam kegitan belajar mengajar terutama untuk pembelajaran kanji karena kemampuan membaca kanji mahasiswa meningkat dan dapat dengan cepat menghafal kanji. Penelitian Prestiani lebih memunculkan alat sebagai media dalam mengatasi kesulitan pembelajaran kanji, namun belum terintegrasi secara online.

Kesulitan ini pun dialami oleh mahasiswa Program Studi Bahasa Jepang di STBA Yapari ABA Bandung, terutama untuk masalah membaca dan mengingat kanji yang levelnya sudah masuk tingkat menegah atau intermediate. Untuk mengatasi masalah yang muncul maka pendidik perlu membuat inovasi dalam pembelajaran. Istagram merupakan salah satu alat yang dapat dimanfaatkan sebagai alat belajar.

\section{Metode Penelitian}

Metode ini menggunakan metode Action Research yang dikembangkan oleh Kemmis dan Mc. Taggart (2005). Hasil pembelajaran kanji di kelas 
ditampilkan kembali melalui visual gambar atau video yang disertai penjelasan atau caption berupa cara baca dari Jepang atau kunyomi dan cara baca dari Cina atau onyomi dan arti kanji tersebut dalam bahasa Indonesia, kemudian unggah ke Instagram dan melihat hasil feedback dari viewer.

Data diambil dari hasil tugas mahasiswa semester lima dalam mata kuliah Kanji Chukyuu 1 dalam bentuk gambar atau video yang memuat kanji dengan cara bacanya dan diunggah ke Instagram.

\section{Hasil dan Pembahasan}

Dengan memanfaatkan media sosial Instagram dalam kegiatan belajar mengajar kanji chukyuu mahasiswa semester lima, penulis sebelumnya meminta mahasiwa untuk mengunggah tugas kanji yang telah dipelajari di kelas ke dalam Instagram dan mahasiswa diharuskan untuk memasukkan tugas tersebut ke fitur \#kanjioftheweek, \#stbayapariaba dan @muhlisian1418 lalu melaporkan hasilnya agar kelompok lain dapat membuat tugas dengan huruf yang berbeda.

Mahasiswa mengunggah hasil mata kuliah kanji chukyuu tersebut dilaksanakan setiap minggu setelah pertemuan perkuliahan selesai, dan di pertemuan selanjutnya, pendidik akan menanyakan kanji yang telah diunggah dalam bentuk quiz untuk mengkonfirmasi kemampuan mahasiswa dalam mengingat kanji.

Data yang sudah terkumpul di fitur \#kanjioftheweek sampai saat ini berjumlah 435 data kanji yang sebagian besar berupa foto kanji disertai gambar latar yang mengandung arti dari kanji tersebut, dan caption yang berisikan cara baca Jepang atau 訓読 dan cara baca Cina atau 音読 juga arti kanji tersebut dalam bahasa Indonesia juga penjelasan mengenai cara mengingat mudah kanji tersebut, seperti pada contoh gambar kanji 争う:あら そう yang mengandung arti berkelahi yang berisi ilustrasi berupa asosiasi gambar tangan yang menggambarkan bentuk kanji 争う, dan kanji 世界: せか 
い yang mengandung arti dunia yang digambarkan dengan latar gambar dunia, seperti di bawah ini:

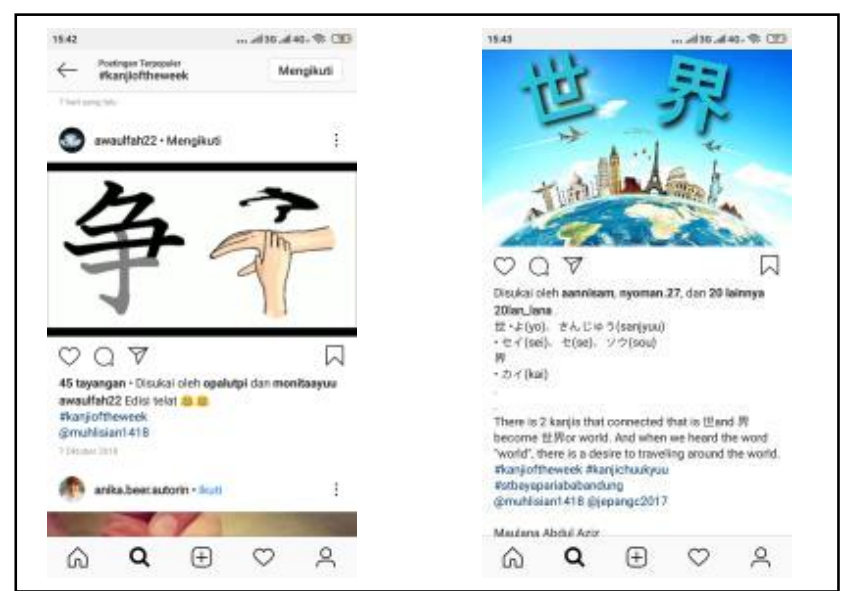

Gambar 1. Penggunaan foto dalam menjelaskan kanji (Sumber. Instagram \#kanjioftheweek)

Namun, ada beberapa mahasiswa membuat tugas kanji dengan memanfaatkan kelebihan dari fitur-fitur yang ada pada Instagram dan memodifikasi tugas kanji tersebut, diantaranya seperti yang dibuat oleh akun Instagram @chaos_heretic atas nama mahasiswa semester 5 kelas B bernama Aryo yang membuat gambar kanji of the week dengan ilustrasi kartun seorang bangsawan dan di slide kedua terdapat kanji 玉 dengan penjelasan cara baca 音読 : オウ、ノウ yang mengandung pengertian king atau raja, juga alasan memposting kanji tersebut dikarenakan kanji tersebut sangat mudah ditulis dan memiliki arti yang mudah dihafal, seperti gambar di bawah ini: 


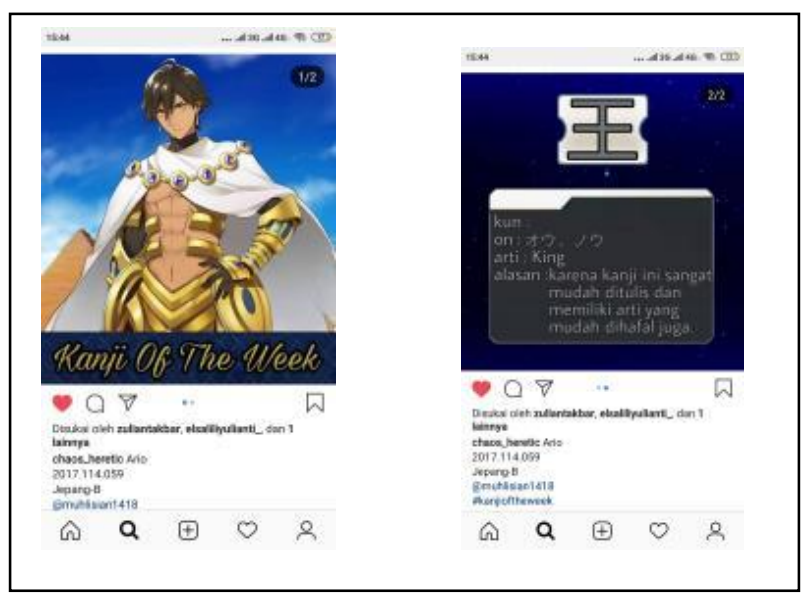

Gambar 2. Penggunaan dua slide dalam menjelasan kanji (Sumber. Instagram \#kanjioftheweek)

Kemudian ada pula yang memanfaatkan fitur video dengan tema yang disesuaikan dengan kanji yang ditampilkan sehingga viewer menjadi lebih tertarik untuk melihatnya karena postingan video yang menarik seperti yang dibuat oleh akun Instagram @yourgaasm atas nama mahasiswa semester 5 kelas C yang bernama Yogasmara yang membuat video kanji tiktok berdurasi sekitar 15 detik yang berisi gambaran kanji 戦う dan diberikan penjelasan cara baca Jepang 訓読：いくさ、たたかう、おののく、そよぐ、わななく pada slide video pertama, penjelasan kanji dan car abaca Cina atau 音読 : セ ン pada slide video kedua dan arti kanji : war, battle, match pada slide video ketiga dan diakhiri dengan ilustrasi perang diakhir video, seperti gambar di bawah ini:

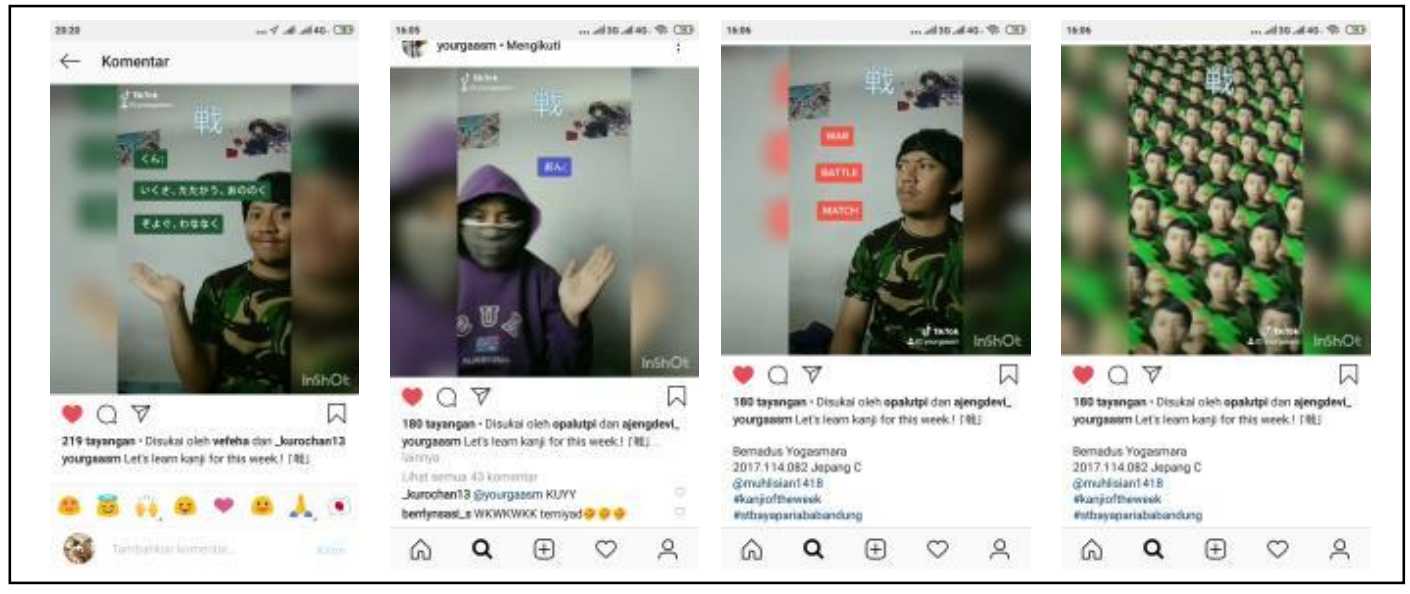


Gambar 3. Penggunaan video ilustrasi dalam menjelasan kanji (Sumber. Instagram \#kanjioftheweek)

selain itu ada juga yang menampilkan video dalam bentuk kanji yang dijelaskan urutan penulisannya 書順 sehingga viewer lebih mudah memahami cara menulis kanji tersebut, seperti yang diposting oleh akun Instagram @kinasihtt atas nama mahasiswa semester 5 kelas A yang bernama Tsania NK yang membuat video kanji dengan penjelasan urutan penulisan dari kanji 仏 dan ilustrasi arti dari kanji tersebut, ditambah dengan caption yang berisi arti dari kanji 仏 yaitu: Buddha, merciful person, Buddhist dan perancis, juga penjelasan 訓読：ほとけ dan 音読 : ブッ, seperti gambar di bawah ini:

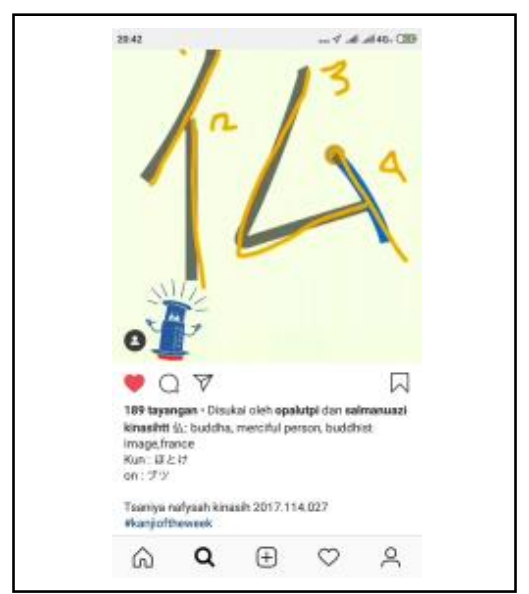

Gambar 4. Penggunaan video urutan cara tulis dalam menjelasan kanji (Sumber. Instagram \#kanjioftheweek)

Dari data unggahan foto dan video terlihat ketertarikan mahasiswa terhadap pembelajaran kanji khususnya pemahaman kanji level chukyuu. Sebagian besar sudah berusaha dengan keras untuk dapat mengingat kanji dengan mengunggah kanji yang telah dipelajari dengan cara unik masing masing mahasiswa sehingga mereka dapat lebih mudah mengingat kanji. Namun masih ada beberapa postingan kanji yang mengunggah kanji yang sama, sehingga ada beberapa kanji yang dipelajari di kelas masih belum terposting oleh mahasiswa, sehingga tujuan penggunaan Instagram untuk mengingat 
kanji masih belum maksimal, namun, dalam kaitannya dengan media yang dipakai untuk pembelajaran kanji sudah terintegrasi dengan baik. Quiz yang dilakukan seminggu setelah kanji diunggah pun menunjukkan hal yang positif, karena mahasiswa menyatakan lebih mudah mengingat kanji yang telah diposting karena ada bentuk asosiasi yang lebih mudah menempel di kepala mahasiswa. Selain dari postngan kanji, penulis pun melihat tanggapan dari pengguna Instagram lain yang sangat positif. Pengguna instagram lain yang melihat hasil unggahan mahasiswa ini banyak yang memberikan komentar positif dan memberikan banyak masukan baik untuk mahasiswa sebagai mengunggah kanji ataupun bagi pengajar.

\section{Kesimpulan}

Instagram sangat memberikan hasil yang baik dan positif kepada mahasiswa semester 5 STBA YAPARI ABA Bandung terutama pada mata kuliah Kanji Chukyuu karena dari 435 mahasiswa yang memposting kanji melalui Instagram, sebagian besar menggunakan fitur-fitur yang ada di Instagram dan menyesuaikannya dengan kemampuan mereka mengingat kanji, seperti dengan asosiasi gambar, video yang menarik dan video urutan penulisan kanji, sehingga mahasiswa pun lebih mudah mengingat kanji saat dilakukan kuiz di kelas.

\section{Referensi}

Aftoniaya, M. N.(2016). Kelebihan dan kekurangan instagram dibanding media sosial lainnya. Diambil dari https://niyasamasa.wordpress.com/2016/12/28/kelebihan-dan-kekuranganinstagram-dibanding-media-sodial-lainnya/

Dahidi, A., \& Sudjianto, M.(2009). Pengantar linguistik bahasa jepang. Jakarta: Kesaint Blanc.

Kominfo.com.(2015). Pengguna internet di indonesia 63 juta orang. Diambil dari http://kominfo.go.id/index.php/content/detail/3415/Kominfo+\%3A+Penggu na+Internet+di+Indonesia 63+Juta+Orang/0/berita_satker. Diakses tanggal 13 Maret 2015

Kemmis, S., \& McTaggart, R. (2005). Participatory action research: Communicative action and the public sphere: Sage Publications Ltd. 


\section{VOL. 3, NO. 2 AGUSTUS 2019

Lensun, S. F. (2016). Peningkatan penguasaan kanji dengan metode nemonik melalui multimedia. Bahtera: Jurnal Pendidikan Bahasa dan Sastra, 15(1).

Muhlisian, A.A.(2018). Penggunaan media sosial instagram dalam praktik pemahaman lintas budaya. Jurnal WA Pendidikan Bahasa Jepang ASPBJI Korwil Jabar Volume 12, Nomor 1, Juni 2018. ISSN: 1979-7982 Hal 25-32

Panji, A. 2014. Hasil survei pemakaian internet remaja indonesia http://tekno.kompas.com/read/2014/02/19/1623250/Hasil.Survei.Pemakaian. Internet.Remaja. Indonesia. Diakses tanggal 11 Maret 2015

Pinchuk P.(2016). Prespective analysis of use of social networks as learning Tools in learning environment. Jurnal of Information Technologies and Learning Tools Vol 54, №. 4. Ukraine.

Pertiwi,W.K.(2018).Riset ungkap pola pemakaian medsos orang indonesia. Kompas. https://tekno.kompas.com/read/2018/03/01/10340027/riset-ungkap-polapemakaian-medsos-orang-indonesia

Prasetiani, D. (2013). Meningkatkan kemampuan membaca kanji melalui media flashcard power point. Izumi, 2(2).

Prensky, M. (2001). Digital natives, digital immigrants part 1. On The Horizon, 9(5), 1-6. 